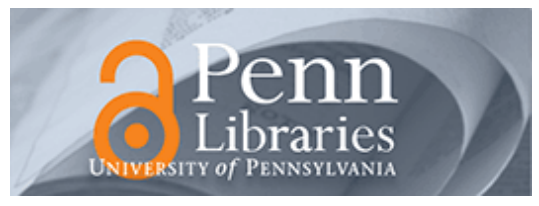

University of Pennsylvania

ScholarlyCommons

Management Papers

Wharton Faculty Research

$10-2017$

\title{
Estimating Value Creation From Revealed Preferences: Application to Value-Based Strategies
}

Olivier Chatain

University of Pennsylvania

Denisa Mindruta

Follow this and additional works at: https://repository.upenn.edu/mgmt_papers

Part of the Management Sciences and Quantitative Methods Commons

\section{Recommended Citation}

Chatain, O., \& Mindruta, D. (2017). Estimating Value Creation From Revealed Preferences: Application to Value-Based Strategies. Strategic Management Journal, 38 (10), 1964-1985. http://dx.doi.org/10.1002/ smj.2633

This paper is posted at ScholarlyCommons. https://repository.upenn.edu/mgmt_papers/232

For more information, please contact repository@pobox.upenn.edu. 


\title{
Estimating Value Creation From Revealed Preferences: Application to Value- Based Strategies
}

\author{
Abstract \\ Research summary: We develop and apply a new set of empirical tools consistent with the tenets of \\ value-based business strategies, leveraging the principle that "no good deal comes undone" and the \\ methods of revealed preferences, to empirically estimate drivers of value creation. We demonstrate how \\ to use these tools in an analysis of value creation in buyer-supplier relationships in the UK corporate \\ legal market. We show that our approach can uncover evidence of subtle mechanisms that traditional \\ methods cannot easily distinguish from each other. Furthermore, we show how the estimates can be \\ used as parameters of biform games for out-of-sample analyses of strategic decisions. With readily \\ available data on relationships between firms, this approach can be applied to many other contexts of \\ interest to strategy researchers. \\ Managerial summary: Managers need to understand the drivers of value creation for customers in order \\ to make competitive positioning decisions and understand when they can capture value under \\ competition. However, estimates of the relative importance of each driver are typically difficult to obtain. \\ In this article, we help remedy this problem by demonstrating a novel method that obtains estimates of \\ the contribution of various drivers of value creation from commonly available data of buyer-supplier \\ relationships. These estimates can then be used to inform the strategy-making process.

\section{Keywords} \\ value-based strategy, revealed preferences, cooperative game theory, buyer-supplier relationships, client- \\ specific economies of scope \\ Disciplines \\ Management Sciences and Quantitative Methods
}




\title{
Estimating Value Creation from Revealed Preferences:
}

\section{Application to Value-Based Strategies}

\author{
Olivier Chatain \\ HEC Paris \\ chatain@hec.fr \\ Denisa Mindruta \\ HEC Paris \\ mindruta@hec.fr
}

December 28, 2016

Forthcoming, Strategic Management Journal

Running head: Estimating Value Creation from Revealed Preferences 


\title{
Estimating Value Creation from Revealed Preferences:
}

\author{
Application to Value-Based Strategies
}

\author{
Running head: Estimating Value Creation from Revealed Preferences
}

\section{Research abstract}

We develop and apply a new set of empirical tools consistent with the tenets of value-based business strategies, leveraging the principle that "no good deal comes undone" and the methods of revealed preferences, to empirically estimate drivers of value creation. We demonstrate how to use these tools in an analysis of value creation in buyer-supplier relationships in the UK corporate legal market. We show that our approach can uncover evidence of subtle mechanisms that traditional methods cannot easily distinguish from each other. Furthermore, we show how the estimates can be used as parameters of biform games for out-of-sample analyses of strategic decisions. With readily available data on relationships between firms, this approach can be applied to many other contexts of interest to strategy researchers.

Word count: 125 words.

Keywords: value-based strategy, revealed preferences, cooperative game theory, buyer-supplier relationships, client-specific economies of scope

\section{Managerial abstract}

Managers need to understand the drivers of value creation for customers in order to make competitive positioning decisions and understand when they can capture value under competition. However, estimates of the relative importance of each driver are typically difficult to obtain. In this paper, we help remedy this problem by demonstrating a novel method that obtains estimates of the contribution of various drivers of value creation from commonly available data of buyer-supplier relationships. These estimates can then be used to inform the strategy-making process.

Word count: 84 words. 


\section{INTRODUCTION}

The notions of value creation and value capture, as introduced to strategic management by Brandenburger and Stuart's (1996) value-based theory, have become a unifying framework for theorizing about firm heterogeneity and competition in competitive strategy research. For instance, use of these notions was instrumental in clarifying central theoretical concepts in the resource-based view (Hoopes, Madsen, and Walker, 2003; Leiblein, 2011; Lippman and Rumelt, 2003). By jointly analyzing value creation and value capture, the value-based framework has provided a structure for linking firm performance and demand characteristics (Adner and Zemsky, 2006; Priem, 2007) and has led to novel insights on how value is captured under competition (MacDonald and Ryall, 2004). This framework has been used to study drivers of strategic advantages in various contexts such as factor markets (Adegbesan, 2009), product markets (Chatain and Zemsky, 2011), and networks (Ryall and Sorenson, 2007).

Given the uptick in applied theorizing offered by the value-based framework, the development of empirical methods specifically tailored to it could greatly benefit strategy researchers and practitioners. Yet a chasm remains between the theoretical advances building on Brandenburger and Stuart $(1996,2007)$ and the empirical work adopting such value-based lens. A prominent limitation is the inability of mainstream empirical methods to identify and estimate parameters of the underlying formal models. Past empirical studies have worked around this problem by relying on proxies of a player's added value ${ }^{1}$ (Adegbesan and Higgins, 2011; Chatain, 2011; Jia, Shi, and Wang, 2012; Obloj and Capron, 2011) and bargaining abilities (Bennett, 2013). These studies find patterns consistent with value-based theory but still fall short of estimating parameters of the theoretical models that generated the empirical predictions.

We argue that to fully exploit the richness of value-based theoretical models, empirical estimation can move beyond corroborating implications of the models to estimating the parameters of the underlying models. Further, researchers equipped with parameter estimates could use the formal models to provide quantitative answers about consequences of strategic actions, such as: What are the returns to improving value creation capabilities? What would happen if a new player entered the competitive interaction? What change in the competitive

\footnotetext{
${ }^{1}$ In the value-based framework, both added value and bargaining ability matter to value capture. The added value of a player is the value that would be lost if the player withdraws from the interaction (Brandenburger and Stuart, 1996). Residual bargaining ability (Brandenburger and Stuart, 2007) is a player's ability to capture value when competition leaves a range of value to be negotiated between firms.
} 
environment would most benefit or threaten a given firm? To reach this goal, scholars need an empirical toolbox that incorporates the assumptions of the value-based theory and provides estimates consistent with it.

By developing such a toolbox, this paper's aim is to put the empirical development of the value-based framework (Brandenburger and Stuart, 1996, 2007; MacDonald and Ryall, 2004) on a par with its theoretical base. Its main contribution is to propose and demonstrate an estimation method derived from the first principles of the value-based framework due to Brandenburger and Stuart $(1996,2007)$ that yields estimates consistent with the assumption of competitive behavior, instead of taking existing econometric methods and imperfectly mapping the value-based framework onto them. The method was originally developed for cooperative game theory models known as matching games (Fox, 2008, 2010), and has been recently applied in the strategic management literature to study alliances (Mindruta, 2013; Mindruta, Moeen, and Agarwal, 2016) while also finding notable applications in marketing (Yang, Shi, and Goldfarb, 2009) and corporate finance (Akkus, Cookson, and Hortaçsu, 2015). We illustrate how it can be further developed to estimate value creation in formal models based on biform games and show how empirical estimates can be leveraged in a model of value capture. This approach is practicable with data that is typically available to strategy researchers, allowing for a wide scope of potential applications.

In the application we describe here, this approach provides deeper insights on the nature of benefits of client-specific scope extensions in a setting where prior studies have suggested their importance. Earlier work (Chatain, 2011) speculated that client-specific economies of scope were largely due to increased value creation occurring from better coordination across tasks. This paper advances upon Chatain (2011) by using data at a finer level of analysis (supplier-buyertask nested in supplier-buyer ties), accounting for the endogeneity of the observed matching thanks to the improved method, and adding more flexibly to the identification of the effect of client-specific scope. The estimates allow for disentangling the relative importance of different mechanisms that can explain seemingly similar patterns in the data. We observe that the positive correlation between client-specific scope and value capture found by Chatain (2011) is the result of the interplay between two opposite forces: the leveraging of costly-to-create relationships, which favors wider scope, and a net cost of extending the scope of existing ties, which favors narrower scope. We find that the benefits of a client-specific scope extension are due to the high 
cost of creating a relationship in the first place rather than direct synergies between tasks. Such a fine-grained difference in findings and interpretation could only be brought about because of our use of a more theoretically consistent method.

The paper is organized as follows: In the next section, we argue the advantages of tightly integrating theory and empirical work for value-based empirical studies. We then use an example to explain the principles upon which our proposed method is based. Finally, we apply the method to the study of value creation in buyer-supplier relationships and illustrate how several questions of interest to strategy scholars can be answered with this approach.

\section{FUNDAMENTAL COMPETITIVE ASSUMPTIONS OF THE VALUE-BASED FRAMEWORK AND THEIR EMPIRICAL IMPLICATIONS}

The value-based framework (Brandenburger and Stuart, 1996, 2007) is a full-fledged theory of value creation and value capture. Traditional econometric methods can test implications of the framework but are ill suited to estimate model parameters. To do so requires building into the methods some key theoretical assumptions of the value-based framework.

\section{Shortcomings of traditional empirical analyses for estimating formal model parameters}

The value-based approach frames the problem of firm performance in terms of value creation, occurring by the transformation of costly input into valuable output by agents working together in a supply chain, and value capture, which is the outcome of competition among agents to appropriate the value created. How much value a firm can appropriate under given conditions is the central question addressed by value-based theory (Brandenburger and Stuart, 1996).

Within this framework, the analysis of value capture requires information on the value creation possibilities (i.e., the value produced in all possible exchanges involving subsets of players in the supply chain) and assumptions on how competition unfolds among those players.

While the theoretical framework was introduced two decades ago, most of the empirical work in this area is relatively recent. The burgeoning empirical literature has made headway in testing implications of value-based theory. For example, Chatain's (2011) study of buyersupplier relationships shows empirical evidence that a supplier's value capture varies with its added value. Bennett (2011) examines factors associated with a player's ability to bargain and shows that these factors influence transaction prices, and thus, value capture. Grennan (2014) empirically estimates bargaining abilities out of a formal model of negotiation between buyers and suppliers in the market for medical devices. A number of other papers have used the 
framework to test relationships between proxies of value creation and dependent variables (e.g., profit, survival) that are commonly studied in strategy (e.g., Adegbesan and Higgins, 2011; Elfenbein and Zenger, 2014; Obloj and Capron, 2011).

To date, however, the empirical literature has given short shrift to the competitive foundations of value-based theory. This is because the idea that observed data is the outcome of a competitive process involving multiple players - a foundation of the value-based approach - is only imperfectly incorporated in traditional regression analyses. More commonly, empirical studies integrate proxies of added value (Capron and Obloj, 2011; Chatain, 2011) or exploit shocks to bargaining abilities (Bennett, 2013) in attempts to exploit indirect implications of the model that can be tested in a traditional fashion.

Fundamentally, standard methods are not able to account for the mutual causation that runs between all observations of ties between firms because these ties form a game-theoretical equilibrium. A given relationship is caused as much by the existence of other relationships that are observed as by counterfactual relationships that are not observed, because all these are simultaneously bound by the equilibrium outcome of the market. Such strategic interdependence is qualitatively different from the statistical dependences that can be conventionally addressed by including control variables or modeling correlation among errors terms.

For these reasons, the existing techniques remain of limited use in exploring what would happen if elements of the strategic interaction under consideration changed. For example, researchers may be interested in understanding how changes in agents' ability to create value would reshape the distribution of value among participants in a transaction. While the formal model accommodates the interdependencies between all parameters touched by a change, the challenge of empirical applications is that traditional, reduced-form, empirical methods require these changes to be observed exogenously in the data. This ideal research environment is most often not achievable, either because changes do not occur as expected, or because systematic field experiments are difficult to run, such as when the unit of analysis is the organization.

Yet the power of formal modeling lies in its providing researchers with the tools to extrapolate observed behavior to predict the impact of "not-yet-observed-changes" (Nevo and Whinston, 2010). To be able to perform an out-of-sample analysis in empirical work, researchers need to have reliable estimates of the theoretical model itself, rather than of its implications, and 
replay the estimated model with different data. To address this challenge, it is necessary to use estimation procedures that are fully consistent with the assumptions of the model.

\section{Competition in value-based models and revealed preferences}

The value-based framework comprises two sets of inputs: assumptions about value creation possibilities and assumptions about competition. While the former are usually easy to parameterize, as in in traditional regression analyses (see, e.g., how different value creation functions are tested and compared in Mindruta, Moeen, and Agarwal [2016]), the latter are still virtually unexploited, hampering progress in the empirical analysis of value-based models.

The assumptions the value-based framework makes about competition are encapsulated in the notion of unrestricted bargaining. Unrestricted bargaining captures the notion of free-form competitive interaction that takes center stage in the theory of value creation and capture presented by Brandenburger and Stuart (1996) and in its biform games extension (Brandenburger and Stuart, 2007). What is underappreciated is that unrestricted bargaining has concrete empirical implications that can be tapped by empirical researchers. These empirical implications provide an opportunity to estimate model parameters from data in a theoretically consistent way, allowing researchers to move beyond reduced-form analyses.

Is important to clarify the meaning of unrestricted bargaining to understand how it maps onto empirical implications. While the word "bargaining" may superficially suggest haggling over a fixed pie, unrestricted bargaining is a more general notion, synonymous with "active deal seeking" by participants in competitive interactions (Brandenburger and Stuart, 1996: 14). Unrestricted bargaining is a strong form of competition that comprises the search for and exploitation of all available value-creating combinations. The essence of unrestricted bargaining can be summarized in the phrase "no good deal goes undone" (Stuart, 2016: 11). Agents acting in a competitive setting will actively search for the best deals available and in the process settle on deals that resist competing offers because they offer superior value to their participants.

This competitive assumption, already found in a key predecessor to the value-based approach (Makowski and Ostroy, 1999), is at the core of the value-based theory (Brandenburger and Stuart, 1996) and its implications are still expounded in theoretical work (Gans and Ryall, forthcoming; Montez, Ruiz-Aliseda, and Ryall, forthcoming).

Empirically, the key is to recognize that combining the knowledge of actual transactions in the data with the assumption that "no good deal goes undone" allows for the systematic 
estimation of the value creation possibilities among buyers and suppliers. The assumption that "no good deal goes undone" constrains how much value counterfactual deals could create relative to those that are observed. These restrictions, stemming from the principle of unrestricted bargaining, can be used as a basis for the estimation of the relative contribution of observable factors to value creation thanks to the logic of revealed preferences, which "refer to people's actual choices in real-world situations" (Train, 2007: 174).

The logic of revealed preferences combines data and restrictions derived from valuebased theory as follows. The principle of unrestricted bargaining (our theoretical engine) asserts that if all agents pursued the best deals available to them, the economic exchanges we observe should provide more value to the parties involved than alternative deals that could have been concluded instead of the observed deals (i.e., counterfactual deals). As a result, to each observed set of deals, we can relate various sets of counterfactual deals that create less value according to the assumption of unrestricted bargaining. We can then systematically compare these two sets of deals (observed and counterfactual) to understand what makes observed deals more valuable.

\section{EXTENDED EXAMPLE}

This extended example provides a primer on the construction of counterfactuals, their comparison to an actual outcome and how this can be used to deduce the contribution to value creation of various drivers. We examine an empirical counterpart to Chatain and Zemsky's (2008) biform game model and show how it can be used in conjunction with data according to the logic of revealed preferences. In their paper, these authors study procurement decisions by buyers who might prefer to purchase from one supplier rather than from several, as well as the

product range positioning decisions of suppliers. Here, we consider the following problem: what can we deduce about the parameters of the model by assuming the data we observe are the outcome of unrestricted bargaining?

\section{Estimating synergies between practice areas}

Assume we can observe the decision of a buyer who has two tasks that need to be taken care of by one or two suppliers. (For simplicity, we neglect unobservable error terms.) The value created when task $a$ is executed by supplier $i$ is denoted $v_{a i}$. We further denote by $R$ the synergy that can be had if the two tasks are given to the same supplier. In keeping with the biform formalism, the efforts to maximize value capture by all parties in the second stage of the biform 
game through unrestricted bargaining lead to the assignment of tasks to suppliers that maximize value creation (Brandenburger and Stuart, 2008).

If the buyer splits its order between supplier 1 for task A and supplier 2 for task B, the value created will be equal to $V=v_{A 1}+v_{B 2}$. If all the work is allocated to firm 1 , the value is equal to $V=v_{A 1}+v_{B 1}+R$. Suppose now that the magnitude of $R$ is unknown but that we know the value parameters. As is typical in econometric approaches, suppose also that we can observe the assignment of suppliers per task that is made by buyers, who themselves know the true value of $R$. As an illustration, Panel 1 of table 1 provides the value created by three suppliers and a buyer who has two tasks.

\section{$===$ Insert Table 1 about here $===$}

Assume that we observe in the data that the buyer is splitting its tasks between firm 1 for task $\mathrm{A}$ and firm 2 for task $\mathrm{B}$. This implies that the value created is equal to $V_{\text {Actual }}=v_{A 1}+v_{B 2}$. What information can be extracted from this observation? A lot can be gleaned by contrasting it with counterfactual assignments - assignments that are creating less value by virtue of the fact that the observed assignment maximizes value. One counterfactual is to give all the work to supplier 3. In that case, the counterfactual value created would be $V_{\mathrm{CF}}=v_{A 3}+v_{B 3}+R$ (the subscript "CF" is for counterfactual).

By the principle of unrestricted bargaining ("no good deal goes undone"), the value created in the observed configuration is by assumption higher than in counterfactuals. Thus:

$$
\begin{gathered}
V_{\text {Actual }} \geq V_{\mathrm{CF}}, \\
v_{A 1}+v_{B 2} \geq v_{A 3}+v_{B 3}+R, \\
20 \geq 16+R .
\end{gathered}
$$

Thus $4 \geq R$, and we have found an upper bound on $R$.

Now, consider another buyer that is facing a different set of potential suppliers and is observed concurrently in the data. Panel 2 of table 1 shows the information available regarding the various value creation scenarios. This buyer is seen to have chosen to give all the work to one single supplier, here supplier 6, creating $V_{\text {Actual }}=v_{A 6}+v_{B 6}+R$.

An alternative not acted upon includes splitting the order between suppliers 4 and 5 and creating $V_{C F_{2}}=v_{A 4}+v_{B 5}$. By assumption, the following inequality must be true:

$$
\begin{gathered}
V_{\text {Actual }} \geq V_{C F_{2}} \\
v_{A 6}+v_{B 6}+R \geq v_{A 4}+v_{B 5}
\end{gathered}
$$




$$
\begin{gathered}
17+R \geq 20 \\
R \geq 3
\end{gathered}
$$

We have thus obtained a lower bound for the value of the parameter $R$. Taken together, the information from the first and the second example leads us to conclude that the value of $R$ is between 3 and 5 .

These analyses, which compare actual and potential value creation, gave us the ability to bracket the possible values that a parameter of interest can take. This process can be generalized (as will be shown below, by drawing on Manski [1975] and Fox [2007, 2008, 2010]) to estimate multiple parameters at the same time, account for fixed effects, and provide confidence intervals, within an approach that gives us a theory-based way to analyze data about value creation in buyer-supplier relationships.

Notice that the method we propose here relies on the premise that competition among firms pushes them to find arrangements that are mutually advantageous and robust to counteroffers (Brandenburger and Stuart, 1996). The assumption that "no good deal goes undone" is fundamental to both extant value-based theory and our estimation method. Moreover, comparing actual and potential value creation in this manner has the following main advantages: (1) little information is needed about the beliefs of the players, and (2) all that matters for the comparison to be relevant for the analysis is that the alternatives (the counterfactuals) be feasible for the firms involved (Pakes, 2010).

\section{Estimating entry cost}

Following the same approach, it is also possible to say something about the costs of creating a relationship. However, it is important to notice that there are limitations to this exercise when these costs are sunk. This idea is made clear by the following example: Consider a firm that needs a supplier to fill a new need. It can either use a current supplier or another supplier. Let $E$ be the sunk, one-off, cost of creating a relationship. (This cost should be understood in terms of the opportunity cost of creating the relationship relative to the expected benefits over the life cycle of the client.) Using the current supplier, the firm can expect to create value in the amount of $V_{\text {Incumbent. }}$. However, the firm could also use an external supplier with which it has never worked, in which case the firm will expect value to be created in the following way, $V=v_{\text {Entrant }}-E$. 
Observing that the entrant is chosen over the incumbent gives us $v_{\text {Entrant }}-E \geq$ $v_{\text {Incumbent }}$ and $v_{\text {Entrant }}-v_{\text {Incumbent }} \geq E$. This gives us a lower bound on $E$. Notice that as long as we consider that $E$ is sunk, it is impossible to get a point estimate or an upper bound on $E$ because we can only observe $E$ being spent, never being recovered.

This is not a weakness of the procedure but rather a consequence of what can be learned from the data without making a strong assumption about the distributions of the unobserved components of value and heavily relying on this assumption. We will not go this path in this paper, as we concentrate on expounding what estimates can be obtained while (1) sticking as much as possible to the spirit of value-based theory, and (2) minimizing extraneous assumptions.

\section{Formation of Counterfactuals}

Key to our method is a rule for listing relevant counterfactual configurations of buyerstasks-suppliers in a systematic, theory-derived way. Based on this rule, we will show how the parameters of the game can be estimated by comparing the value created in observed and counterfactual configurations. To this end, we exploit the nature of the equilibrium underlying the buyer-tasks-supplier(s) relationships observed in the data.

To derive this rule, we focus on a necessary condition that should be satisfied by every assignment of a buyer's tasks to suppliers, once all players' first-stage strategic choices to collaborate (i.e., who transacts with whom among buyers and suppliers) have been decided in the market. When "no good deal goes undone," the value generated by an observed assignment of a buyer's tasks to suppliers cannot be improved upon by reallocating a task to another supplier already serving the buyer. Equivalently stated, the value created by the actual assignment of tasks to suppliers should be greater than the value created by any assignment that reallocates one task at a time from one supplier to another, while all other task-supplier pairings remain unchanged for that buyer. By applying this rule to all buyer-supplier relationships, we create a set of inequalities that constitutes the basis for estimation.

We illustrate the creation of counterfactuals with a simple example (Figure 1). The top panel, titled "Observed configuration for a given buyer," describes the observed assignment of tasks (labeled A, B, and C) to suppliers (labeled 1, 2, and 3) for buyer $k$. Task A is fulfilled by supplier 1. Task B is fulfilled by both supplier 1 and supplier 2, which is an indication of dual sourcing, while task $\mathrm{C}$ is fulfilled only by supplier 3 .

$===$ Insert Figure 1 about here $===$ 
The middle panel of Figure 1, titled "Creation of counterfactuals most similar to observed configuration," shows six counterfactual assignments, obtained by applying the above-mentioned rule to the observed assignment. To build a counterfactual assignment, we take one pair of observed task-supplier matching and replace it by a counterfactual matching of the same task with one of the suppliers that is not currently supplying that task. This last point is important as it takes care of potential issues with dual sourcing. For concreteness, consider the observed pairing \{task A by supplier 1\}. In counterfactual CF1 we replaced supplier 1 with supplier 2 (thus, CF1 now contains $\{$ task A by supplier 2$\}$ ), while the other task-supplier pairings stayed the same (i.e., \{task B by supplier 1\}, \{task B by supplier 2$\}$, \{task C by supplier 3$\}$ ). Compared to the observed configuration, supplier 1 has reduced its scope (it now serves only task B), while supplier 2 has increased its client-specific scope (it now serves both task A and task B, instead of just task B). In counterfactual CF2, for task A, we replaced supplier 1 with supplier 3 and kept all other task-supplier pairings constant. This time, supplier 3 increased its client-specific scope, at the expense of supplier 1 .

An interesting situation is the construction of counterfactuals involving task B. Because supplier 1 and supplier 2 are both assigned to this task in the observed data, we can only replace them, in turn, by supplier 3. As before, task $\mathrm{A}$ and task $\mathrm{C}$ continue to be assigned to their current suppliers, supplier 1 and supplier 3, respectively. Thus, the counterfactual configuration CF3 contains the following pairings: $\{$ task A by supplier 1$\}$ (unchanged), $\{$ task B by supplier 3$\}$ (modified in the counterfactual), and \{task B by supplier 2$\}$ and $\{$ task $\mathrm{C}$ by supplier 3$\}$ (both unchanged). Likewise, CF4 is composed of $\{$ task A by supplier 1$\}$ and $\{$ task B by supplier 1$\}$ (both unchanged), \{task B by supplier 3$\}$ (modified in the counterfactual), and \{task C by supplier 3 \} (unchanged).

Following this method, we obtained six counterfactuals. In all these counterfactuals, one supplier takes on one additional task and another supplier loses one task compared to the observed assignment. Once counterfactuals are formed, they are used to generate the necessary conditions about value creation. This is shown in Figure 1's bottom panel, titled "Pairwise comparison of value creation: observed vs. counterfactual." These conditions assert that the value created in the observed configuration is greater than the value created in the counterfactual configurations. 
The approach we underlined here has several advantages. Inequalities are necessary conditions that hold for all observed configurations involving a buyer, its suppliers, and the assignment of the buyer's tasks to actual suppliers. These conditions are consistent with a biform game in which the collaboration of buyers and suppliers and the assignment of the buyer's tasks to suppliers emerge as buyers and their suppliers maximize the joint surplus given the competitive environment (Chatain and Zemsky, 2007). Note that we only need to assume that the observed choices create more value than the simple-to-construct counterfactuals we consider, not necessarily any possible counterfactual.

Second, the construction of counterfactuals provides relevant information for the estimation of the effect of variation in client-specific scope. In the potential, unrealized assignment, the actual supplier loses one task, while the newly assigned supplier takes on an additional task and thus increases its client-specific scope relative to that actually realized. This procedure allows us to estimate the impact of a change in the supplier's client-specific scope on value creation because it focuses on the variation of client-specific scope in the counterfactuals.

Third, the counterfactual formation rule controls for the heterogeneity among buyers. All exchanges involve reassigning a buyer's tasks to suppliers who are already serving the buyer. Therefore, the interaction terms between buyer attributes (including buyer-task characteristics) and supplier attributes have the same effect on value creation in both the actual and counterfactual configurations.

Fourth, the counterfactual formation rule keeps the demand of the clients constant, as in the actual data. Indeed, reassignments keep the make-or-buy and dual-sourcing decisions of the buyer unchanged. The counterfactual creation method enables creating variation in the clientspecific scope but does not require asking what would happen if buyers internalized a task or if they switched from dual sourcing to single sourcing or vice versa.

Lastly, counterfactual assignments are built within the existing relationships between a buyer and its suppliers and do not impose the condition that buyers create new supplier relationships. Reassigning tasks to existing suppliers keeps the focus of the estimation on the effect of variation in client-specific scope. On the contrary, the creation of new collaborations between buyers and other suppliers is required when the focus is on the matching of buyers and 
suppliers and firms are assumed to have capacity constraints (see, e.g., Fox [2008] for an example). ${ }^{2}$

A feature that the formation of counterfactuals in our approach shares with the discrete choice methods is the exploitation of information from the revealed preferences of the players regarding the pairing of suppliers and tasks. There are, however, major differences between the discrete choice models and the inequalities-based approach (see discussion in Mindruta et al. 2016, pp. 215-218 and Appendix S2). Notably, the inequalities-based approach does not impose a distribution on the error terms, nor does it assume the independence of irrelevant alternatives, and thus require fewer and less restrictive assumptions for estimation.

\section{Formal definitions}

Recall that counterfactual formation involves taking one task at a time and reallocating it to a different supplier, while all other supplier-task pairings remain unchanged for a given buyer. Let $a$ denote one of the tasks of buyer $k$. Holding the rest of the supplier-task pairings constant, one can focus on comparing the value created by the discrete assignment of actual supplier $i$ to task $a$ with the value of the counterfactual assignment of a supplier $j$ to task $a$. Denote $n_{i k}$ the client-specific scope of supplier $i$, i.e., the count of the number of tasks that supplier $i$ takes care of for buyer $k$.

The incremental value $\Delta \mathrm{V}_{\mathrm{ik}}^{\text {Actual }}(a)$ created by the actual supplier $i$ with observed scope of $n_{i}$ while taking on the $n_{i}$-th task $a$ of buyer $k$ can be written formally as:

$$
\Delta V_{i k}^{\text {Actual }}(a)=W T P_{a i}-C_{a i}+s_{n_{i k}}+\lambda_{a k}+\varepsilon_{a i k}
$$

Equation (1) means that the incremental value created is a function of the buyer's willingness to pay for having supplier $i$ on task $a\left(W T P_{i a}\right)$; the supplier $i$ 's opportunity cost for this task $\left(\mathrm{C}_{\mathrm{ai}}\right)$; and $s_{n_{i k}}$, the incremental change in value from increasing the client-specific scope of supplier $i$ from $n_{i k}-1$ (the scope of supplier $i$ if it were not to supply area $a$ ) to $n_{i k}$ (its actual scope). We also include a buyer-task fixed effect $\lambda_{a k}$ and an error term $\varepsilon_{a i k}$. Note that the error term should be interpreted as representing evaluation errors or any additional information not observed by the researcher that agents take into account prior to deciding on the allocation of tasks.

\footnotetext{
${ }^{2}$ Fox (2007) compares the sum of the value created by two actual buyer-supplier pairs (e.g., A-X and B$\mathrm{Y})$ to that of pairs where the partners are exchanged (A-Y and B-X). This approach underlies Mindruta's (2013) study of alliance formation.
} 
As it is central to our analysis, the formulation of incremental change $s_{n_{i}}$ deserves elaboration. Formally, $s_{n_{i}}$ is the product of the vector $S=\left(s_{2}, s_{3}, \ldots, s_{N}\right)$ of incremental change of value of client-specific scope for scope breadth of $2\left(s_{2}\right)$ up to the maximum possible in the data $\left(s_{N}\right)$, with the supplier-specific vector of indicator variables $D_{i}=\left(d_{2}, d_{3}, \ldots, d_{N}\right)$ such that $d_{n}$ is equal to 1 if the observed scope of supplier $i$ is equal to $n$, and zero otherwise.

In the counterfactual assignment, task $a$ is given to supplier $j$. As a result, supplier $j$ increases its client-specific scope from an observed $n_{j k}$ to the counterfactual level of $n_{j k}+1$, which means that we need to include $s_{n_{j k}+1}$, rather than the observed $s_{n_{j k}}$, in the incremental value formula for the counterfactual. Thus, the incremental value that results from giving task $a$ to supplier $j$ is written:

$$
\Delta V_{j k}^{C F}(a)=W T P_{a j}-C_{a j}+s_{n_{j k}+1}+\lambda_{a k}+\varepsilon_{a j k}
$$

For each task, the marginal value equations (1) and (2) disentangle the effect of suppliers' value creation abilities to execute the task and the impact of a discrete change in the level of client-specific economy of scope. The terms willingness to pay $\left(W T P_{a i}\right.$, respectively $\left.W T P_{a j}\right)$ and $\operatorname{cost}\left(C_{a i}\right.$, respectively $\left.C_{a j}\right)$ capture the heterogeneity in value creation across suppliers and tasks. In the empirical application, this feature of the model allows for suppliers to be strong in some tasks and weak in others. The terms $s_{n_{i k}}$ and $s_{n_{j k}+1}$ capture the idea that adding an extra task to a supplier's assignment may modify the joint value created. Thanks to these terms, the model allows for the value created to depend on the number of tasks that are carried out by a supplier, in addition to a supplier's ability to create value in any particular task. Moreover, the model is agnostic regarding the sign of the $s_{n}$ terms, which may be different depending on $n$. Two alternative scenarios are plausible. If there is an optimal number of tasks to be grouped for a given supplier, we would expect $s_{n}$ to be positive for lower values of $n$ and decreasing up to the optimal $n$. Alternatively, suppose that undertaking any additional work involves fixed costs that are not related to the number of tasks a supplier fulfills for any given buyer. In this case we would expect $s_{n}$ to be negative for any level of $n$.

The assumption of unrestricted bargaining married with revealed preference implies that, holding other allocations constant, the incremental value created by assigning a supplier to a task is higher in the actual than in the counterfactual allocation:

$$
\Delta \mathrm{V}_{\mathrm{ik}}^{\text {Actual }}(a)>\Delta V_{j k}^{C F}(a)
$$


Equivalently:

$$
W T P_{a i}-C_{a i}+s_{n_{i k}}+\varepsilon_{a i k}>W T P_{a j}-C_{a j}+s_{n_{j k}+1}+\varepsilon_{a j k}
$$

Importantly, the buyer-task effect $\lambda_{\mathrm{ak}}$, which was on both sides of the inequality, cancelled out. Indeed, these comparisons are made within alternative assignments of tasks to the existing suppliers of each individual buyer, which has the advantage of controlling for unobserved heterogeneity at the buyer-task level and, implicitly, at the buyer level.

Panel 3 of Figure 1 illustrates the pairwise comparison of value creation for the example discussed in panels 1 and 3 of the same figure.

\section{Context and Data: The UK Corporate Legal Market}

\section{Context}

The empirical context for this study is the UK corporate legal market in the years 2002 to 2006. The corporate clients (i.e., the buyers) are among the 250 largest market capitalizations of the London Stock Exchange and the suppliers are large British law firms (among the top 100 by size) and the London offices of large U.S. law firms. ${ }^{3}$

The data on buyer-supplier relationships come from a survey conducted by Client Report, an industry trade magazine targeted at general counsels. The first four years of those data were also used in Chatain (2011). The survey was addressed to the general counsels of the corporate clients and produced a very high response rate. General counsels exposed the list of their main legal advisers and the legal areas in which they used them (i.e., the tasks). The definition of legal areas is the one commonly used in the industry and by market research firms. Table 2 shows one of these lists, detailing the legal supplier base of British Airways in 2005.

$$
===\text { Insert Table } 2 \text { about here }===
$$

In the data, law firm-client relationships typically lasted several years: the average yearly rate of law firm-client relationship termination was only $12.7 \%$. Clients maintained multiple relationships simultaneously, with each client using yearly an average of 3.76 law firms. Over the time span of the study, the trend was toward contracting with more firms, with the average number of law firms per client at 3.17 in 2002 but rising steadily each year, to 4.25 in 2006 ( $t$ test of difference in mean is significant at $p<0.0001$ ). Clients needed advice in 4.48 legal areas

\footnotetext{
${ }^{3}$ We use the term "client" for "buyer," "law firm" for "supplier," and "legal area" for "task" when referring to the details of the empirical context.
} 
on average. With multiple law firms and multiple areas of work, the structure of the client-law firm interface is quite complex.

On the one hand, clients may use a law firm across multiple legal areas. In the sample, $35.8 \%$ of client-law firm relationships spanned more than one area in a given year. These relationships, involving a client-specific scope superior to 1 , accounted for $59.2 \%$ of all arealevel observations. In other words, most sourcing decisions are taken against a backdrop of frequent cross-selling. On the other hand, clients may sometimes use different suppliers for the same area of legal work. In the Client Report survey, dual sourcing, whereby a given area of work is divided among several suppliers, concerned $21.7 \%$ of the year-firm-area cases. By construction, instances of concurrent sourcing (Parmigiani and Mitchell, 2009) are not reported in the survey.

Moreover, the allocation of areas of legal work to suppliers appears more fluid than the relationships between buyers and suppliers, showing a process of dynamic reallocation over time. At the area level, excluding cases where the need for the area went away, the yearly rate of termination was $26.8 \%$, more than twice the rate of termination of overall relationships (12.7\%). Similarly, there was a yearly $40.0 \%$ rate of addition of suppliers at the area level.

The emerging picture is consistent with previous research in the same setting (Chatain, 2011), showing that buyers facing a need in a new legal area are much more likely to pick one of their existing suppliers rather than an outsider. This is also consistent with work in the U.S. corporate legal context (Coates, DeStefano, Nanda, and Wilkins, 2011) showing that clients maintain multiple deep relationships with law firms, while at the same time pick for specific areas those they think are the best fit.

To get a sense of the concentration of the procurement and the role of cross-selling, we compared the frequency of cross-selling in the data to that of a simulated benchmark where client areas are randomly and independently allocated to law in proportion to the law firms' actual market share for the type of area. This preserves the law firms' level of activity, but forces cross-selling to only occur by chance, muting the role of client-specific scope while preserving that of law firms' capabilities. Figure 2 compares the actual distribution of client-specific scope (the number of areas a law firm sells to a client) with the simulated distribution. Strikingly, most of the areas $(79.1 \%)$ in the simulated data are part of relationships of scope equal to 1 (no crossselling), while the majority of observed ties (59.2\%) are in relationships of scope equal to 2 or 
more (indicating cross-selling). This shows that clients and law firms undertake a lot more crossselling than chance would explain. Our empirical analysis will explore why.

$===$ Insert Figure 2 about here $===$

Sample

Over the five-year span of 2002 to 2006, there were a total of 1,229 answers (out of a possible maximum of 1,250), each constituted by the set of law firms working for a client and the legal areas in which they were involved for this client, for a total of 7,291 year-client-firmarea observations. The constraints imposed by the scope of the estimation and limitations on the availability of cost data restricted the analysis to 5,502 buyer-task-supplier ties (75.5\%) out of the 7,291 originally given in the survey. Because the method exploits the variation within a buyer's supplier base, we dropped buyers that either used only one firm for all their needs or mentioned only one type of legal need. Moreover, the information on quality and cost was missing for some suppliers mentioned in the survey. The lack of ranking (quality) data on quality is captured by a dummy variable. We dropped the observations for which cost was not available.

The remaining 119 law firms included in the analysis are the largest and most prominent in the market. Given the overlap with the top 100 law firm rankings, our sample captures a large share of the legal business conducted in the UK in numbers of lawyers and turnover (Cole, 2004) and, presumably, the lion's share of the corporate legal business. In our final sample, the average number of law firms per client is slightly higher than in the full survey data (3.98 vs. 3.77), as is the proportion of ties that are part of cross-selling relationships (62.1\% vs. 59.2\%). The breakdown of legal areas by type remains very similar.

The number of combinations of legal areas and locations (London, rest of England and Wales, Scotland) is very large. The most commonly found legal area and place was corporate finance in London (17.4\% of observations). One law firm garnered $16.1 \%$ of the ties, while the average market share was $8.6 \%$. The largest market share in the top 19 legal areas (which together comprise $80.8 \%$ of the ties) was $26.3 \%$ (banking in London), suggesting that alternative suppliers were usually available to clients.

\section{Variables}

This setting offers fine-grained data on the span of buyer-supplier relationships. At noted before, our empirical strategy implicitly includes buyer-year fixed effects, removing the need to control for time-varying buyer characteristics. 
Quality ratings. As a proxy for willingness-to-pay for expertise, we used the yearly recommendations for law firms in multiple legal areas produced by Chambers and Partners, the parent firm of Client Report. We relied on publicly available financial data on the top law firms to construct a proxy for the cost of production. These sources of data are reviewed in turn.

We derived the ratings of quality from the yearly reports published by Chambers and Partners' Guides to the UK Legal Profession. Each guide presents the rankings of recommended firms in over 60 areas of law. This guide has been consistently published every year since 1990 and is acknowledged as one of the two leading providers of information about the UK legal market. The guide is a result of six months of research (January to June) by a team of 30 lawyers and legal journalists. Firms are ranked within tiered lists. According to Chambers and Partners, the rankings are meant to reflect "technical legal ability, professional conduct, client service, commercial awareness/astuteness, diligence, commitment, and other qualities that the client considers relevant" (Ghosh, 2005). We used these rankings to construct the supplier quality rating, which takes values between 0 and 1 , from lowest to highest ranking. We created a separate dummy variable for suppliers not being listed (no ranking). When the quality ratings are matched to the buyer-supplier relationship data, there is a higher proportion of ties going to suppliers with higher ratings, reflecting a correlation between rating and law firm market share in the FTSE 250. While examining buyer-supplier relationships in a given year, we use the previous year's information on rankings.

Opportunity cost of lawyers. We used financial information available for the top $100 \mathrm{UK}$ law firms and top 25 foreign law firms in London to create a proxy for the cost of providing legal services. We compiled this information from the yearly league tables provided by the trade publications Legal Business and The Lawyer. We constructed a measure of cost per lawyer, calculated by dividing the total cost of a firm by its number of practicing lawyers, including partners and non-partners. This metric is widely reported in league tables and used in trade journals.

The main component of the costs of a law firm consists of salaries for administrative staff members and lawyers who are not partners. The opportunity cost of these employees can be measured by their salaries, which can be thought of as reflecting their marginal product in the job market and thus the value of their next best use in the economy. In contrast, the opportunity cost of partners is not as easily measured. For our purpose, we will assume it is equal to zero in the 
short run. The reason is that partners are committed to the law firm and cannot switch jobs as easily as a salaried lawyer in the short run. Moreover, while constructing counterfactuals, we made the assumption that firms were not capacity constrained, which enabled them to take another piece of business if available. As partners have some capacity to spare, no value creation is forgone in the short run and the opportunity cost is zero. As a result, the ratio of total cost to total number of lawyers (salaried lawyers and partners) can be understood as a proxy for the short-run opportunity cost of the firm's main suppliers.

Relationship length. In order to account for accumulated relationship-specific experience, we create a variable that indicates that a spell of relationship is left-censored. We also count the number of years a relationship is observed between the client and the law firm.

Table 3 shows the descriptive statistics and cross-correlations at the area level for clientspecific scope, cost per lawyer, quality rating, no ranking, left-censored relationship, and relationship length.

\section{$===$ Insert Table 3 about here $===$}

\section{Estimation}

To form the estimator, we first rewrite the marginal value expressions (1) and (2) into their empirical counterparts, replacing each theoretical term by its corresponding variable in the dataset and the parameters to be estimated $\left(\alpha, \beta, \delta_{2}, \ldots, \delta_{N}\right)$. In a basic specification, the willingness-to-pay component of the formulas becomes $\alpha \cdot$ Rating $_{a i}$ (or $\alpha \cdot$ Rating $_{a j}$ ), where $\alpha$ is the parameter to estimate. Likewise, the opportunity cost component is replaced by the costper-lawyer variable and the parameter $\beta$ to estimate, $\beta \cdot C p l_{i}$ (or $\beta \cdot C p l_{j i}$ ). The influence of scope on value creation is measured by the vector of parameters $\left(\delta_{2}, \ldots, \delta_{N}\right)$, which is the empirical counterpart to the vector $\left(s_{2}, \ldots, s_{N}\right)$. In keeping with equations (1) and (2), $s_{n_{i}}$ is replaced by $\delta_{n_{i k}}$ and $s_{n_{j}+1}$ is replaced by $\delta_{n_{i k}+1}$ in equations (5) and (6).

We thus obtain the following expressions for the empirical counterparts of the marginal value equations:

$$
\begin{aligned}
& \Delta V_{i k}^{\text {Actual }}(a, \Theta)=\alpha \cdot \text { Rating }_{a i}-\beta \cdot C p l_{i}+\delta_{n_{i k}}+\lambda_{a k}+\varepsilon_{a i k}, \\
& \Delta V_{j k}^{C F}(a, \Theta)=\alpha \cdot \text { Rating }_{a j}-\beta \cdot C p l_{j}+\delta_{n_{j k}+1}+\lambda_{a k}+\varepsilon_{a j k} .
\end{aligned}
$$

Taken together, the expressions (1) - (6) lead to the following inequality:

$$
\alpha \cdot \text { Rating }_{a i}-\beta \cdot C p l_{i}+\delta_{n_{i k}}+\varepsilon_{a i k}>\alpha \cdot \text { Rating }_{a j}-\beta \cdot C p l_{j}+\delta_{n_{j k}+1}+\varepsilon_{a j k}
$$


In the estimation procedure we seek to find the set of parameters $\Theta=\left(\alpha, \beta, \delta_{2}, \ldots, \delta_{N}\right)$ that satisfies the highest number of inequalities (7) in the data. Technically, the estimates are those that maximize the following objective function:

$$
Q(\Theta)=\sum_{k \in K} \quad \sum_{a \in A_{k}} \quad \sum_{i \in M_{a k}} \sum_{j \in M_{k} /\{i\}} \mathbf{1}\left\{\Delta V_{i k}^{\text {Actual }}(a, \Theta) \geq \Delta V_{j k}^{C F}(a, \Theta)\right\}
$$

In this equation, $K$ is the set of buyers, $M_{a k}$ is the set of suppliers serving buyer $k, A_{i k}$ is the set of tasks that supplier $i$ is fulfilling for buyer $k$ and $\mathbf{1}\{\cdot\}$ is an indicator function, equal to 1 when the expression in brackets is true, and 0 otherwise. The indicator function $\mathbf{1}\{\cdot\}$ takes a value of 1 if the inequality $\Delta V_{i k}^{A c t u a l}(a, \Theta) \geq \Delta V_{j k}^{C F}(a, \Theta)$ is true for parameters $\left\{\alpha, \beta, \delta_{2}, \ldots, \delta_{N}\right\}$. The function $Q(\Theta)$ then sums these indicator functions over all tasks and all buyers.

The function $Q(\Theta)$ is a step function. To find its maximum (and thus, the coefficient estimates for which the maximum is attained), we follow Santiago and Fox (2009) and apply the differential evolution algorithm (Storn and Price, 1997). We compute the confidence intervals around the point estimates using the subsampling procedure (Politis, Romano and Wolf, 1999), which gives consistent estimates for the maximum score estimator. ${ }^{4} \mathrm{We}$ implement the estimation in Mathematica 10.0 by adapting the toolkit developed and made available by Santiago and Fox (2009).

This estimator relies on a minimal assumption concerning the error term: the rank order property for probability of choice. This assumption states that when comparing two alternatives, the one with the highest value, net of the error term, has a higher probability of being selected, Importantly, this assumption does not impose a specific distribution on the error terms, and arbitrary patterns of heteroskedasticity are permitted (Horowitz, 1998: 71). The estimator is consistent, even when it is only used over a subset of the choices available (Fox, 2008). Further, the estimator performs well in small samples and situations where the logit model is misspecified (Fox, 2008). ${ }^{5}$

\footnotetext{
${ }^{4}$ Subsampling draws samples without replacement, while the bootstrap draws samples with replacement. The bootstrap is inconsistent when used with a maximum score estimator (Abrevaya and Huang, 2005). Subsampling is more conservative, requiring weaker assumptions on the distribution of the unobservables, but converges at a lower rate (cube root of sample size) than the bootstrap (square root). ${ }^{5}$ The maximum score estimator was originally developed for a discrete choice model by Manski (1975). Fox $(2007,2008,2010)$ develops this line of research and shows that the maximum score estimator can be used for estimations based on necessary conditions formulated as inequalities.
} 
As in discrete choice models, the estimator requires a scale normalization on the vector $\Theta=\left(\alpha, \beta, \delta_{2}, \ldots, \delta_{n}\right)$ (Fox, 2010). We follow the standard procedure and impose that one coefficient (here, the coefficient $\alpha$ of the rating variable) has the value of \pm 1 , which will scale the other coefficient estimates. The sign of this coefficient is identified by choosing it to be the sign that yields a better fit of the model. To this purpose, we run each model specification twice, once for $\alpha=1$ and once for $\alpha=-1$, and we choose the sign returning a higher number of predicted inequalities. Consistent with the expectation that supplier rating has a positive effect on value creation, the positive sign of the rating has always led to a better model fit in our sample.

\section{Results}

Results are shown on Table 4. Column 1 shows a baseline model including quality rating as the scaling factor, the cost per lawyer, and a dummy for the case when the law firm is not ranked at all. The $95 \%$ confidence interval for the cost per lawyer variable is entirely below zero.

In column 2, we introduce further variables to account for the length of a relationship between a law firm and its client. The effect associated with the left-censored variable, which picks up the possibility that there is already an ongoing relationship of unknown length between the law firm and the client, is small and positive. This magnitude is not surprising as the variable pools existing long-lasting relationships with relationships that have just started. The relationship length variable counts the number of years a relationship has been observed in the data between the law firm and the client. It is indistinguishable from zero at conventional levels of significance. The cost per lawyer remains negative (95\% confidence interval $[-3.38,-0.39])$.

\section{$===$ Insert Table 4 about here $===$}

Column 3 refines the analysis by introducing the possibility of a non-linear effect with a squared relationship length as a variable. The magnitude of the effect is very small, even if it sits in the $90 \%$ confidence interval away from zero. Moreover, the explanatory power of the model (percentage of inequalities correctly predicted) is virtually unchanged, at about $77 \%$. While we cannot rule out the nonlinear effects, they do not seem explain enough of the phenomenon, and we will not pursue this path further.

In column 4, we introduce the main set of variables of interest: dummy variables capturing the incremental benefit from changes in client-specific scope when moving away from the observed level of scope (breadth) of the relationships. These are the variables $\delta_{2}$ to $\delta_{5}$, with $\delta_{n}$ estimating the value created or lost if the client-specific scope attains $n$, starting from $n$ - 1 . 
Because there are few instances when the client-specific scope of a law firm is higher than 5 in the data, we created one dummy $\left(\delta_{5}\right)$ to capture all changes in scope higher than 5 .

The introduction of dummy variables of scope extension markedly improves the fit of the model (see column 4). Now, $87 \%$ of the inequalities are correctly predicted. The $95 \%$ confidence intervals of these variables are all clearly bounded away from zero. All coefficients are strongly negative, with magnitude above 1 , which means that extending the client-specific scope by one additional area has more impact on value creation than an improvement in reputation rating that would take a firm from not being ranked to the top of the rankings. Meanwhile, the estimated coefficient for costs and not being ranked become hard to distinguish from zero, while the left censored variable keeps its magnitude.

In unreported analyses, we restricted the sample to counterfactuals involving either the more reputed law firms or those with a history of repeated transactions with the focal client. By focusing on law firms that clients have arguably the most information on, our goal was to test whether the results were sensitive to the definition of the set of alternatives that the clients might consider. The results were similar to those involving the full sample, indicating that our main results are not driven by the inclusion of potentially irrelevant counterfactuals.

These estimates, which by construction take into account the value creation alternatives available in a configuration of client-law area-supplier, suggest that a lot of value is lost in the relationships by increasing marginally the scope of the supplier. This is consistent with the idea that incremental benefits from scope become gradually exhausted until they become smaller than the inevitable, though small, fixed costs associated with scope extension.

This finding does not result mechanically from the way the estimates were calculated. Under the null hypothesis, the observed scope would be explained only by the merits of each firm in terms of quality, cost, and relationship length, and existing scope levels would not matter for value creation. Accordingly, the estimates of scope increase variables would be equal to zero as the current preferences for the allocation of suppliers to tasks would be purely explained by variables other than the client-specific economies of scope.

There are two other plausible scenarios in the buyer-supplier setting. In a first scenario, if scope extensions (net of intrinsic quality and costs) are triggered by a better ability to create synergies at higher levels of client-specific scope, we could plausibly observe small positive values for the coefficients capturing the increase in scope. Then, broader scope would still be 
beneficial at the observed margin, but no more extension would happen when suppliers lack intrinsic ability in the areas they do not serve (as measured by the rankings). Secondly, it is possible that scope extensions might already destroy value at lower levels of operation, but that these losses are still less costly than the alternative of creating a relationship with a supplier lacking prior experience with the client. Here, we would expect a negative impact on value creation of the marginal scope increase. We will probe this explanation later when we estimate a lower bound on the cost of creating a relationship.

The results strongly suggest that there are no more gains (but actually losses) to scope expansion beyond the observed levels in the sample, leaving open the question of the nature and magnitude of the marginal gains to a wider client-specific scope on value creation. Indeed, while scope extensions beyond the observed scope are value destructive, it does not mean that this is also necessarily true for scope extensions at lower levels of breadth (i.e., when suppliers are executing one or a small number of tasks for a buyer). By design, the thought experiment underlying our estimates does not formally estimate how changes in client-specific scope affect value creation when these changes are far away from the observed levels of client-specific scope. This is because the changes we estimate are only of one task more or less than what is observed.

However, we can estimate whether there is a total effect of breadth on value creation. By introducing the breadth of scope (number of areas served) as a variable in the model, we can test if there is an intrinsic preference for breadth, keeping in mind that the marginal return of scope increase is negative. The results, presented in column 5 , show a negative and weak total effect of scope on value. The dummies for scope extension are removed due to collinearity issues. The hardly distinguishable from zero coefficient of the breadth of scope could be interpreted as the sum of positive effects up to the point where they become negative, as found in the previous regressions. It implies moderate positive effects across tasks when clients and suppliers gradually increase the breadth of their relationship. However, these effects are exhausted at the observed level of scope.

\section{APPLICATION: USING THE ESTIMATES TO ASSESS STRATEGIC DECISIONS}

A natural way to take advantage of the empirical estimates of value creation to gain a better understanding of competition in the UK corporate legal market is to use these coefficients in conjunction with simple cooperative games. We now analyze a few fictional situations involving clients and law firms. The goal is to show how the estimates of the factors driving 
value creation obtained in the previous section can be used to provide concrete advice to firms involved in competitive interactions.

\section{Seizing a new opportunity and the cost of creating a new relationship}

When a buyer has a new legal need, a new opportunity is offered to existing suppliers. However, this opportunity represents a new competitive ground as suppliers vie to capture it. Factoring in both capability and scope can help us understand better for whom, and to what extent, the new opportunity can be profitable. Consider the example depicted in Table 5.

\section{$===$ Insert Table 5 about here $===$}

The buyer has had needs for three areas of business (i.e., tasks; columns 1 to 3 ) and now needs services in another area 4 (column 4). It is currently using two suppliers. Each cell of the table gives the rating and the cost of a supplier's work in a given area. An X designates when a supplier is actually working on the task for the buyer. We see that supplier 1 works on task 1 , while supplier 2 works on tasks 2 and 3.

For simplicity, we assume that all the error terms in equation (1) and (2) are equal to zero. In this example, supplier 1 is serving the buyer in area 1, while supplier 2 is serving the buyer in areas 2 and 3. Notice that this arrangement is value maximizing assuming that the cost of creating a buyer-supplier relationship is sunk. Cost variables are set at identical values across suppliers so that they do not affect decisions. The ratings for suppliers 1 and 2 are, for the moment, left at unspecified values Rating $_{1}$ and Rating $_{2}$, respectively.

Given current scope and capabilities, which supplier is better placed to profitably serve the buyer in area 4? Compare the increments of value that each supplier would be able to create if it were to serve area 4 in addition to those it already serves, using rounded values of the estimates from model 5 of Table 4.

Supplier 1's incremental value created is superior to that of supplier 2 if and only if:

$$
\begin{aligned}
& \text { Rating }_{1}-\beta \cdot \text { Cost }+\delta_{2}>\text { Rating }_{2}-\beta \cdot \text { Cost }_{2}+\delta_{3} \\
& \text { Rating }_{1}-\beta \cdot \text { Cost }- \text { Rating }_{2}+\beta \cdot \text { Cost }_{2}>\delta_{3}-\delta_{2}
\end{aligned}
$$

The combined quality and cost advantage of supplier 1 over supplier 2 should be more than the difference between dis-synergies associated with a scope increasing to 3 for supplier 1 and to 2 for supplier 2 (i.e., $\delta_{3}-\delta_{2}$ ). Replacing the symbols by the estimated values, the condition can be rewritten as:

$$
\text { Rating }_{1}-\text { Rating }_{2}>-1.80+1.85=0.05
$$


This gap in ratings can be compared to the standard deviation of 0.30 found for the quality variable in the sample. The comparatively lower increase in dis-synergies that supplier 2 would have to deal with only gives it a minimal advantage. Unless the gap in quality between the two suppliers is relatively high, the buyer will be able to extract a lot of value by pitting the two suppliers against each other.

Now modify the example so that supplier 2's scope is equal to 3 (instead of 2). The capability advantage required so that supplier 1 is creating more value is equal to:

$$
\text { Rating }_{1}-\text { Rating }_{2}>\delta_{4}-\delta_{2}=-1.48+1.85=0.37
$$

This is a much higher hurdle to overcome. At that level of client-specific scope, supplier 2's incremental penalty from scope expansion (-1.48) is lower than supplier 1's (-1.85), which represents a substantial gap of 0.37 - more than one standard deviation in the rating measure. Because it has a wider client-specific scope and there are some relative increasing returns associated with broader scope, supplier 2 has an advantage.

\section{Estimating the cost of creating a new buyer-supplier relationship}

Armed with these estimates, we can calculate lower bounds for the cost of adding another buyer-supplier relationship and expanding the set of alternative suppliers. We start from the following observation: If client-specific scope extensions are value reducing, as we found in the analysis, and yet buyers are not taking steps to restrict suppliers' client-specific scope, the implication is that the cost of expanding scope is less than that of creating an additional buyersupplier relationship. We explore this idea in the simplest case that consists of reducing the scope of an existing supplier from $n$ to $n-1$ and adding a new supplier with client-specific scope equal to 1 . Formally, consider the value creation of actual supplier $i$ with overall client-specific scope $n_{i}$ in task a, and compare it to the alternative of creating a relationship with supplier $j$ at $\operatorname{cost} R$. Omitting fixed effects (which cancel out) and assuming other unobservables are equal to zero, we have:

$$
\begin{array}{r}
W T P_{a i}-C_{i}+s_{n_{i}}>W T P_{a j}-C_{j}-R \\
R>-S_{n_{i}}+\left(W T P_{a j}-W T P_{a i}\right)+\left(C_{i}-C_{j}\right)
\end{array}
$$


This inequality is valid for all instances of one supplier having a client-specific scope equal or superior to two tasks and it defines a lower bound $R^{L B}$ on $R$.

We can make several assumptions on the extent of the difference in value creation between $j$ and $i$, net of scope effects. A neutral assumption is to consider that the buyer could find a similar supplier so that $W T P_{a i}-\operatorname{Cost}_{j}=W T P_{a j}-$ Cost $_{i}$. Another, more optimistic assumption is that the buyer could establish a relationship with the best alternative supplier possible, the one for which $W T P_{a j}-$ Cost $_{j}$ is maximum among all suppliers.

Taking these assumptions to the data with the estimates from model 4 of Table 4 , we can compute a lower bound for the cost of creating a relationship in the status quo scenario of no improvement in supplier value creation $\left(R_{\text {Status }}^{L B}\right.$ uo $)$, and another, tighter (i.e., of superior value) lower bound in the best alternative supplier scenario $\left(R_{B e s t}^{L B}\right.$ Alternative $)$. Table 6 shows the results of these calculations, and Figure 3 shows the empirical cumulative distribution of the values for

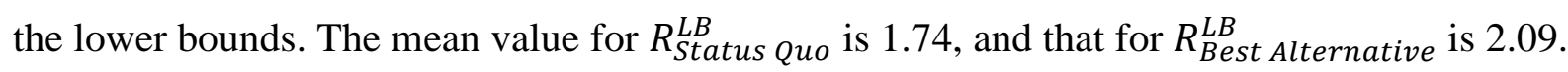
These are substantially high values, given that they are expressed in units of quality rating, with the value of 1 corresponding to the gap between the lowest-ranked firm and the top firm.

$===$ Insert Figure 3 and Table 6 about here ===

\section{DISCUSSION AND CONCLUSION}

\section{Implications for value creation in vertical relationships and supplier horizontal scope}

Previous work has argued that when a supplier is simultaneously performing different tasks for one client, additional value creation could be achieved via client-specific scope economies (Chatain and Zemsky, 2007). Our estimates show a cost of extending scope within existing relationships. This cost is the net result of (dis)economies of scope coming from the demand side (clients) and the supply side (suppliers) as well as from their interaction. We cannot distinguish between the two directly from our estimates, which means that there are potentially multiple mechanisms at play.

On the demand side, and given an already existing relationship, a number of reasons may explain why a client might be wary to let a supplier increase its client-specific scope. First, a broader client-specific scope could bring in fears of conflicts of interest. However, in this setting, the norm is not to deal with a client in any capacity if there is the smallest conflict of interest even in a different legal area, ruling out this concern. Another possibility is that clients may be afraid of being held up in the future and purposely refrain from allocating a large a share of their 
legal work to any given supplier. However, if this were the only reason for negative scope effect, we would expect estimated coefficients to be become more negative as scope increases, which is not consistent with the pattern uncovered by our analysis. Finally, it can be that clients value a diversity of opinions across suppliers and that they are afraid of putting too much weight on any given supplier. Overall, when looking at demand-side factors, such preferences for diversity of opinion or of sources of supply could partially explain the negative result.

On the supply side, a key driver of the cost of expanding scope may be the up-front cost that a law firm has to bear when acquiring knowledge specific to the client in a new legal area. Further, it is possible that internal conflicts could make the coordination between tasks more costly for integrated than for distinct providers. For instance, partners within the integrated firm may inefficiently spend time and resources to determine who is in charge of a particular client. Alternatively, the costs can reflect the existence of binding capacity constraints in undertaking additional legal workload. However, due to the relative elasticity of supply of partner work (Chatain and Meyer-Doyle, Forthcoming), such constraints are not prevalent in the sample. Overall, on the supply side, we believe that the simplest explanation is the existence of costs of expanding due to learning about the client, even though other types of costs cannot be ruled out.

Given all these considerations, why do scope extensions occur in spite of the patterns of dis-synergies found in the value creation function? Our analysis suggests that suppliers may achieve scope economies by economizing on the cost of creating a relationship, rather than by reducing costs within the existing relationships. Starting a new relationship is subject to set-up costs and the estimate of the lower bound of these costs is substantially high. Some of these costs can be due to the need to invest in relationship-specific assets, routines, and knowledge (Crawford, 1990; Dyer and Singh, 1998). Forming new relationships may also be subject to higher governance-related costs than continuing an existing relationship, as new ties occur under the shadow of potential holdup (Klein, 1996), while existing relationships are sustained by the value of relational contracts (Baker, Gibbons and Murphy, 2002; Board, 2011). In Board's (2011) model, the cost of creating a new relationship is a manifestation of a buyer's deliberate bias toward current suppliers, which is intended to reduce the probability of holdup by guaranteeing them enough value capture if the relationship is sustained. In sum, the high cost of creating a relationship that we found could be a combination of costly relationship-specific investments (time and resources), and governance-related bias toward insiders. 
While the interpretation in terms of relational contracts emphasizes the rationality of such bias, another interpretation is that this bias represents a form of cognitive lock-in (Uzzi, 1997). However, qualitative evidence in a comparable empirical context pictures astute clients consciously maintaining a balance of close relationships (creating bias toward insiders) and competition between insiders when allocating specific tasks (Coates et al, 2011), which gives less credence to a cognitive lock-in interpretation. In sum, even though we are not able to fully untangle the mechanisms driving the effects of dis-synergies and new relationship creation on value creation, there is evidence that several opposing forces are simultaneously at work.

Future research can help further unpack these mechanisms and enrich those that are taken into account in the analysis. Two venues are worth investigating. The first is to produce a finergrained understanding of the value of co-specialization between buyers and suppliers. For this analysis, measures of the potential for co-specialization at the level of the product could be introduced, as in Elfenbein and Zenger (2014). The second venue is to explore potential sources of complementarities between tasks. Such analysis could also be incorporated in the same revealed preference framework, by adding indicator variables for additional value created (or destroyed) when the same supplier does two specific types of tasks.

\section{Implications for empirical work in value-based strategies}

The results speak to the inter-firm relationship literature, but the paper's broader motivation is to demonstrate how combining the fundamental assumptions of value-based theory (Brandenburger and Stuart, 1996) with the logic of revealed preferences can enable further empirical progress beyond early work demonstrating correlations (Chatain, 2011) or treatment effects (Bennett, 2011) consistent with the theory. By exploiting the information in the completed transactions and systematically analyzing how these transactions differ from welldefined counterfactuals, our approach makes it possible to estimate the relative importance of various drivers of value creation. While prior work, such as Fosfuri and Giarratana (2009), has focused on the effect of competitive actions (e.g., advertising, product introduction) on value capture by an individual firm (e.g., Tobin's Q) we provide a step forward toward fully decomposing the causal path going from firm investment to firm profit via value creation.

In addition to buyer-supplier relationships, the methods developed in this paper can be applied to most datasets listing observed relationships in supply chains, network of firms and ecosystems. The essential data requirements are observations of existing trading relationships 
and the definition of a set of credible counterfactuals. In this respect, our empirical method follows a similar heuristic to that underlying recent theoretical work by Gans and Ryall (forthcoming) and Montez, Ruiz-Aliseda, and Ryall (forthcoming).

\section{Implications for practitioners}

Our method expands how practitioners can use data for strategy analysis by analyzing strategic interactions "out of the sample". With the parameters estimated from data taken from real situations, cooperative games can be applied to understand the challenges faced by the various players. For instance, it is possible to quantify the trade-offs between value creation from capability and from client-specific scope, which allows for an understanding of the relative strength of firms in different competitive scenarios. Matching these analyses of the competitive environment with an internal analysis of what a given firm can do and at what costs would provide a complete picture of the trade-offs a firm faces and would be a valuable tool for decision making with respect to resource allocation and organizational commitments.

\section{Limitations}

Our results should be viewed in light of some important boundary conditions and limitations given our parsimonious model of value creation. A key assumption of this paper ('unrestricted bargaining') implies that firms can contemplate many different deals prior to determining the final allocation of tasks to suppliers. This assumption fits well in the context of our analysis: corporate clients can easily shift from a current law firm to another since there are no long term contracts in this setting, and prospective partners, having ongoing relationships, know each other very well. Moreover, even though law firms usually bill hourly rates, they have latitude to adjust their billings if necessary to keep clients happy. However, this assumption may not be appropriate in settings where institutions prevent bargaining and instead favor take-it-orleave-it offers (e.g., auctions, posted prices) or where institutions are inadequate to protect exchanges so that there is less bargaining (and transactions) than expected (e.g., appropriability concerns in the markets for technology). Alternatively, it might be that bargaining is possible but that the set of partners who are attainable is limited due to frictions (Chatain and Zemsky, 2011). In this latter case, our method is still applicable but will likely produce less precise estimates as there are fewer relevant counterfactuals to be constructed.

Another issue is that of selection into the sample studied, leading us to overestimate the severity of the cost of scope expansion. Our analysis did not use data on clients who dealt 
exclusively with one law firm because in this case there are no counterfactuals to be constructed. If exclusive relationships involved suppliers who were unusually good at creating synergies between tasks, our estimates of synergies would be potentially biased downward as these suppliers were selected out of the sample. However, in our data, all but one of the law firms who were in a position of single-sourcing were also supplying other clients and were otherwise very well represented in the data we exploited. This aspect alleviates the concern that the negative coefficients of scope expansion were driven by the composition of the sample. Another interpretation is that some clients had a stronger preference for single sourcing and selected themselves into having exclusive relationships, hence dropping out of the sample. This scenario opens the possibility that our estimates of the value created by scope extension might be biased downward compared to the population average due to selection on the client side.

Finally, the counterfactuals assume that capacity constraints on the supply side are not binding (suppliers can serve one more area in the counterfactuals). The negative sign on the scope extension coefficients could be interpreted as evidence for such capacity constraints. However, interviews with actors in the market never revealed capacity constraints as a reason for not serving a client. Instead, there is evidence that partners of law firms can go to great length to ensure that they can serve all the needs of their clients, either by stretching themselves thin or by redistributing work within their firm (Chatain and Meyer-Doyle, Forthcoming).

\section{Conclusion}

In this paper, we developed and applied a new set of empirical tools for scholars in the value-based stream of research. We relied on the idea that "no good deal comes undone," a foundational principle of the value-based approach, to develop empirical analyses relying on revealed preferences to estimate drivers of value creation. Thanks to this novel approach, we analyzed data on buyer-supplier relationships in the UK corporate legal market and uncovered evidence for mechanisms that traditional methods could not easily distinguish from each other. Future work could rely and expand on this methodology in many settings of interest to strategic management and provide estimates of drivers of value creation that are theoretically consistent with the competitive assumptions of the value-based framework. 


\section{ACKNOWLEDGEMENTS}

We thank the Editor, Will Mitchell, and two anonymous referees for their help in shaping the paper. We thank Matthew Bidwell, Ramon Casadesus-Masanell, Alon Eizenberg, Émilie Feldman, Jeremy Fox, Rahul Kapoor, Jerry Kim, Ethan Mollick, Felipe Monteiro, Anne Parmigiani, and Evan Rawley, as well as participants in the 2009 HBS Strategy Research Conference, the Strategy Research Forum, and seminars at Harvard Business School, Columbia Business School, and Bocconi University, for their comments and suggestions on previous versions of this paper, circulated under the title "Where Do Client-Specific Scope Economies Come From? A Revealed Preference Analysis." The financial and material support of the Mack Institute at the Wharton School, University of Pennsylvania, is kindly acknowledged. All errors remain our own.

\section{REFERENCES}

Adegbesan JA, Higgins MJ. 2011. The intra-alliance division of value created through collaboration. Strategic Management Journal 32(2): 187-211.

Adegbesan T. 2009. On the origins of competitive advantage: strategic factor markets and heterogeneous resource complementarity. Academy of Management Review 34(3): 463475.

Adner R, Zemsky P. 2006. A demand-based perspective on sustainable competitive advantage. Strategic Manage Journal 27(3): 215-239.

Akkus O, Cookson JA, Hortaçsu A. 2015. The determinants of bank mergers: a revealed preference analysis. Management Science. Articles in advance.

Baker G, Gibbons R, Murphy KJ. 2002. Relational contracts and the theory of the firm. Quarterly Journal of Economics 117(1): 39-84.

Board S. 2011. Relational contracts and the value of loyalty. American Economic Review 101(7): 3349-3367.

Bennett V. 2013. Organization and bargaining: sales process choice at auto dealerships. Management Science 59(9): 2003-2018.

Brandenburger AM, Stuart HW. 1996. Value- based business strategy. Journal of Economics \& Management Strategy 5(1): 5-24.

Brandenburger A, Stuart HW. 2007. Biform games. Management Science 53(4): 537-549.

Chatain O. 2011. Value creation, competition, and performance in buyer-supplier relationships. Strategic Management Journal 32(1): 76-102.

Chatain O, Meyer-Doyle P. Forthcoming. Alleviating managerial dilemmas in human-capitalintensive firms through incentives: Evidence from M\&A legal advisors. Strategic Management Journal. DOI: 10.1002/smj.2473

Chatain O, Zemsky P. 2007. The horizontal scope of the firm: organizational tradeoffs vs. buyersupplier relationships. Management Science 53(4): 550-565.

Chatain O, Zemsky P. 2011. Value creation and value capture with frictions. Strategic Management Journal 32(11): 1206-1231.

Coates JC, DeStefano MM, Nanda A, Wilkins DB. 2011. Hiring teams, firms, and lawyers: evidence of the evolving relationships in the corporate legal market. Law \& Social Inquiry 36(4): 999-1031.

Cole B. 2004. Trends in the solicitors' profession, annual statistical report 2004. The Law Society. London. 
Crawford V. 1990. Relationship-Specific Investment. The Quarterly Journal of Economics 105(2): 561-574.

Dyer JH, Singh H. 1998. The relational view: cooperative strategy and sources of interorganizational competitive advantage. Academy of Management Review 23(4): 660679.

Elfenbein DW, Zenger T. 2014. Creating and capturing value in repeated exchange relationships: managing a second paradox of embeddedness. Available at SSRN 1649464. Available at: http://papers.ssrn.com/sol3/papers.cfm?abstract_id=1649464.

Fosfuri A, Giarratana MS. 2009. Masters of War: Rivals' Product Innovation and New Advertising in Mature Product Markets. Management Science 55(2): 181-191.

Fox, JT. 2007. Semiparametric estimation of multinomial discrete-choice models using a subset of choices. RAND Journal of Economics 38(4): 1002-1019.

Fox JT. 2008. Estimating matching games with transfers. National Bureau of Economic Research Working Paper 14382. Available at: http://www.nber.org/papers/w14382.

Fox JT. 2010. Identification in matching games. Quantitative Economics 1(2): 203-254.

Gans JS, Ryall MD. Value capture theory: a strategic management review. Strategic Management Journal [In press].

Grennan M. 2014. Bargaining ability and competitive advantage: empirical evidence from medical devices. Management Science 60(12): 3011-3025.

Ghosh R. 2006. Chambers UK: A Client's Guide to the UK Legal Profession, 2005-2006. Chambers \& Partners Legal Publications. London.

Hoopes DG, Madsen TL, Walker G. 2003. Guest editors' introduction to the special issue: why is there a resource- based view? Toward a theory of competitive heterogeneity. Strategic Management Journal 24(10): 889-902.

Horowitz JL. 1998. Semiparametric Methods in Econometrics, Springer-Verlag. New-York.

Jia N, Shi J, Wang Y. 2012. Value creation and value capture in corporate governance: using the value-based approach to analyze an ownership reform of china's listed firms. SSRN Scholarly Paper. Social Science Research Network: Rochester, NY. Available at: http://papers.ssrn.com/abstract=2171355.

Klein B. 1996. Why hold-ups occur: the self-enforcing range of contractual relationships. Economic Inquiry 34(3): 444-463.

Leiblein MJ. 2011. What do resource- and capability-based theories propose? Journal of Management 37(4): 909-932.

Lippman SA, Rumelt RP. 2003. A bargaining perspective on resource advantage. Strategic Management Journal 24(11): 1069-1086.

MacDonald G, Ryall MD. 2004. How do value creation and competition determine whether a firm appropriates value? Management Science 50(10): 1319-1333.

Makowski L, Ostroy JM. 2001. Perfect competition and the creativity of the market. Journal of Economic Literature 39(2): 479.

Manski CF. 1975. Maximum score estimation of the stochastic utility model of choice. Journal of Econometrics 3(3): 205-228.

Mindruta D. 2013. Value creation in university-firm research collaborations: a matching approach. Strategic Management Journal 34(6): 644-665.

Mindruta D, Moeen M, Agarwal R. 2016. A two-sided matching approach for partner selection and assessing complementarities in partners' attributes in inter-firm alliances. Strategic Management Journal 37(1): 206-231. 
Montez J, Ruiz-Aliseda F, Ryall MD. Forthcoming. Quantifying the negative-and positiveeffects of competitive intensity on firm performance. Management Science

Nevo A, Whinston MD. 2010. Taking the Dogma out of Econometrics: Structural Modeling and Credible Inference. Journal of Economic Perspectives, 24(2): 69-82.

Obloj T, Capron L. 2011. Role of resource gap and value appropriation: effect of reputation gap on price premium in online auctions. Strategic Management Journal 32(4): 447-456.

Obloj T, Zemsky P. 2015. Value creation and value capture under moral hazard: exploring the micro-foundations of buyer-supplier relationships. Strategic Management Journal 36(8): 1146-1163.Pakes A. 2010. Alternative models for moment inequalities. Econometrica 78(6): 1783-1822.

Pakes A, Porter J, Ho K, Ishii J. 2015. Moment inequalities and their application. Econometrica 83(1): 315-334.

Parmigiani AE, Mitchell W. 2009. Complementarity, Capabilities, and the Boundary of the Firm: The Impact of Within-firm and Interfirm Expertise on Concurrent Sourcing of Complementary Components. Strategic Management Journal 30(10): 1065-1091.

Ryall MD, Sorenson O. 2007. Brokers and competitive advantage. Management Science 53(4): $566-583$.

Santiago D, Fox JT. 2009. A toolkit for matching maximum score estimation. University of Chicago.

Stuart HW. 2016. The Profitability Test. The MIT Press. Cambridge MA.

Train K. 2003. Discrete Choice Methods with Simulation. Cambridge University Press. New York

Uzzi B. 1997. Social Structure and Competition in Interfirm Networks: The paradox of embeddedness. Administrative Science Quarterly 42(1): 35-67.

Yang Y, Shi M, Goldfarb A. 2009. Estimating the value of brand alliances in professional team sports. Marketing Science 28(6): 1095-1111. 


\section{TABLES}

Table 1. Value creation scenarios in the extended example

\begin{tabular}{|c|c|c|c|c|c|}
\hline \multicolumn{3}{|c|}{ Panel 1} & \multicolumn{3}{|c|}{ Panel 2} \\
\hline Supplier & $v_{A i}$ & $v_{B i}$ & Supplier & $v_{A i}$ & $v_{B i}$ \\
\hline 1 & 10 & 0 & 4 & 10 & 0 \\
\hline 2 & 3 & 10 & 5 & 3 & 10 \\
\hline 3 & 8 & 8 & 6 & 9 & 8 \\
\hline
\end{tabular}

Table 2. British Airways' suppliers of legal services (2005)

\begin{tabular}{ll}
\hline \multicolumn{1}{c}{ Law firm (supplier) } & \multicolumn{1}{c}{ Area of legal service (task) } \\
\hline Addleshaw Goddard & Commercial \\
Addleshaw Goddard & Employment \\
Addleshaw Goddard & TMT \\
\hline Baker \& McKensie & Employment \\
\hline Bristows & IP \\
\hline Gates \& Partners & Aviation \\
Gates \& Partners & Insurance \\
\hline Slaughter and May & Corporate finance \\
Slaughter and May & Projects \\
Slaughter and May & Tax \\
Slaughter and May & Commercial \\
\hline Wragge \& Co LLP & IP \\
Wragge \& Co LLP & Litigation \\
Wragge \& Co LLP & Property \\
\hline
\end{tabular}


Table 3. Descriptive statistics and correlation table

\begin{tabular}{l|llll|llllll}
\multicolumn{1}{c}{ Variable } & Mean & S.D. & \multicolumn{1}{c}{ Min } & \multicolumn{1}{c}{$\operatorname{Max}$} & (1) & (2) & (3) & (4) & (5) \\
\hline (1) & Client-specific scope & 2.22 & 1.31 & 1 & 9 & 1 & & & & \\
(2) & Cost per lawyer & 0.16 & 0.04 & 0.05 & 0.47 & 0.05 & 1 & & & \\
(3) & Quality ranking & 0.69 & 0.30 & 0 & 1 & -0.03 & -0.05 & 1 & & \\
(4) & Not ranked & 0.09 & 0.29 & 0 & 1 & 0.04 & 0.05 & -0.73 & 1 & \\
(5) & Left-censored rel. & 0.79 & 0.41 & 0 & 1 & 0.17 & -0.01 & 0.08 & -0.11 & 1 \\
(6) & Relationship length & 2.36 & 1.33 & 1 & 5 & 0.22 & 0.08 & 0.13 & -0.09 & 0.22 \\
\hline
\end{tabular}


Table 4. Estimation results

\begin{tabular}{|c|c|c|c|c|c|}
\hline Model & (1) & (2) & (3) & (4) & $(5)$ \\
\hline \multirow[t]{2}{*}{ Quality rating } & +1 & +1 & +1 & +1 & +1 \\
\hline & N/A & N/A & N/A & N/A & N/A \\
\hline \multirow[t]{2}{*}{ Cost per lawyer } & -1.34 & -1.20 & -1.22 & -0.21 & -0.27 \\
\hline & {$[-3.47,-0.62]$} & {$[-3.38,-0.39]$} & {$[-3.27,-0.42]$} & {$[-2.91,0.62]$} & {$[-4.72,0.95]$} \\
\hline \multirow[t]{2}{*}{ Not ranked } & -0.15 & -5.23 & -4.23 & -0.33 & -3.80 \\
\hline & {$[-0.33,108.81]$} & {$[-8.50,-1.40]$} & {$[-6.78,-0.23]$} & {$[-0.52,0.11]$} & {$[-5.36,4.48]$} \\
\hline \multirow[t]{2}{*}{ Left censored } & & 0.24 & 0.21 & 0.39 & 0.46 \\
\hline & & {$[0.07,0.62]$} & {$[-0.01,0.57]$} & {$[0.05,0.86]$} & {$[-0.55,1.03]$} \\
\hline \multirow[t]{2}{*}{ Relationship length } & & -0.04 & -0.28 & -0.06 & -0.07 \\
\hline & & {$[-0.30,0.06]$} & {$[-0.81,0.04]$} & {$[-0.31,0.11]$} & {$[-0.41,0.15]$} \\
\hline \multirow[t]{2}{*}{ Relationship length squared } & & & 0.05 & & \\
\hline & & & {$[-0.01,0.14]$} & & \\
\hline \multirow[t]{2}{*}{$\delta_{2}$} & & & & -1.85 & \\
\hline & & & & {$[-2.23,-1.32]$} & \\
\hline \multirow[t]{2}{*}{$\delta_{3}$} & & & & -1.80 & \\
\hline & & & & {$[-2.22,-1.23]$} & \\
\hline \multirow[t]{2}{*}{$\delta_{4}$} & & & & -1.48 & \\
\hline & & & & {$[-1.89,-0.97]$} & \\
\hline \multirow[t]{2}{*}{$\delta_{5}$ and more } & & & & -1.49 & \\
\hline & & & & {$[-1.90,-0.97]$} & \\
\hline \multirow[t]{2}{*}{ No. of other areas served } & & & & & -0.45 \\
\hline & & & & & {$[-0.57,0.47]$} \\
\hline No. inequalities & 17763 & 17763 & 17763 & 17763 & 17763 \\
\hline No. inequalities satisfied & 13615 & 13658 & 13662 & 15409 & 14345 \\
\hline Percentage inequ. satisfied & $76.6 \%$ & $76.9 \%$ & $76.9 \%$ & $86.7 \%$ & $80.8 \%$ \\
\hline Estimation time & 2.29 & 7.86 & 11.82 & 13.54 & 11.32 \\
\hline Number subsamples & 1000 & 1000 & 1000 & 1000 & 1000 \\
\hline Subsampling time & 1077.35 & 3012.44 & 4693.72 & 6708.20 & 4819.24 \\
\hline
\end{tabular}

Note: Subsampled asymmetric $95 \%$ confidence intervals in brackets. 
Table 5. Current allocation of tasks to suppliers and supplier characteristics

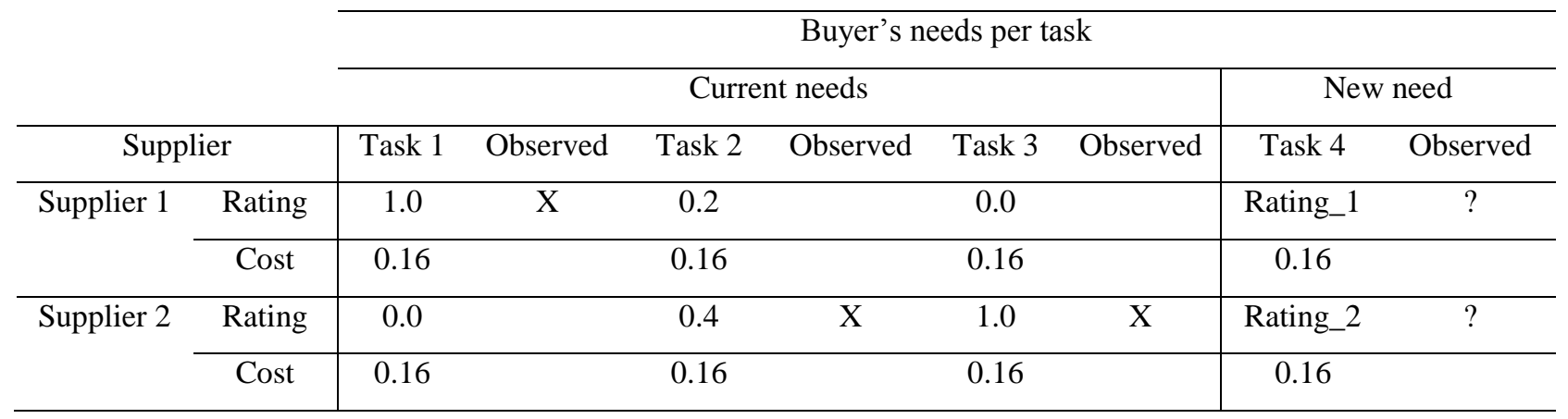

Table 6. Implied lower bounds on cost of search and relationship creation

\begin{tabular}{c|cccc}
\hline Lower bound & Mean & Median & Min. & Max. \\
\hline$R_{\text {Status Quo }}^{L B}$ & 1.74 & 1.80 & 1.48 & 1.85 \\
\hline$R_{\text {Best Alternative }}^{L B}$ & 2.09 & 2.03 & 1.48 & 3.73 \\
\hline
\end{tabular}

Notes: The estimations are scaled by the quality variable. The lower bound on the cost of entry is obtained by computing the value that would be saved by reducing the scope of a current supplier if its scope is 2 or more, and substituting it by an outside supplier. The logic is that the cost of search and relationship creation has to be at least as high as this figure to rationalize why buyers are not creating an extra relationship with a supplier. In the calculations for $R_{\text {Status } Q u o}^{L B}$, the outside supplier is assumed to create as much value as the supplier currently serving the buyer.

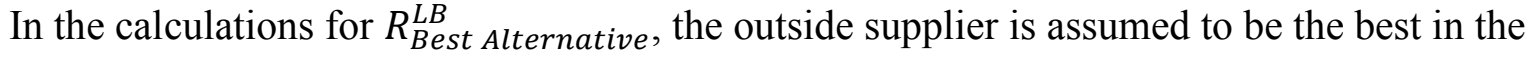
market in terms of quality-cost wedge. The estimates from model 4 of Table 4 were used to quantify the contributions of quality and cost to value creation. A total of 3,415 cases were used. 


\section{Observed configuration for a given buyer}

Buyer $k$, suppliers 1, 2, 3 and tasks A, B, and C

\begin{tabular}{|lllll|}
\hline & & \multicolumn{3}{c}{ Tasks } \\
\cline { 3 - 5 } Assignment & & A & B & C \\
\hline Observed: & Supplier(s) & 1 & 1,2 & 3 \\
\hline
\end{tabular}

\section{Creation of counterfactuals most similar to observed configuration}

One single task assigned differently from the observed configuration

\begin{tabular}{|c|c|c|c|c|c|}
\hline \multirow{2}{*}{\multicolumn{2}{|c|}{$\begin{array}{l}\text { Counterfactual } \\
\text { assignments }\end{array}$}} & \multicolumn{3}{|c|}{ Tasks } & \multirow{8}{*}{$\begin{array}{l}\text { One supplier } \\
\text { takes one more } \\
\text { task, another } \\
\text { loses one }\end{array}$} \\
\hline & & \multirow{2}{*}{$\frac{A}{2}$} & \multirow{2}{*}{$\frac{B}{1,2}$} & \multirow{2}{*}{$\frac{C}{3}$} & \\
\hline CF 1: & Supplier & & & & \\
\hline CF 2: & Supplier & 3 & 1,2 & 3 & \\
\hline CF 3 : & Supplier & 1 & 3. 2 & 3 & \\
\hline CF 4: & Supplier & 1 & 1,3 & 3 & \\
\hline CF 5: & Supplier & 1 & 1,2 & 1 & \\
\hline CF 6: & Supplier & 1 & 1,2 & 2 & \\
\hline $\begin{array}{l}\text { Tas } \\
\text { in th }\end{array}$ & $\begin{array}{l}\text { hat is alloc } \\
\text { counterfac }\end{array}$ & & ntly fr & & onfiguration \\
\hline
\end{tabular}

\section{Pairwise comparison of value creation: observed vs. counterfactual}

Each counterfactual provides a comparison to the observed allocation that is used to create necessary conditions

\begin{tabular}{|c|c|}
\hline$\Delta V^{A}$ ctual (Observed: $A$ by Firm 1) $>\Delta V^{C F}$ (CF 1: A by Firm 2) & \\
\hline$\Delta V^{\text {Actual }}$ (Observed: $A$ by Firm 1) $>\Delta V_{C F}$ (CF 2: A by Firm 3) & $\begin{array}{l}\text { Necessary } \\
\text { conditions for }\end{array}$ \\
\hline$\Delta V^{\text {hctual }}$ (Observed: $B$ by Firm 1) $>\Delta V^{C F}$ (CF 3: B by Firm 3 ) & $\begin{array}{c}\text { observed } \\
\text { allocation to }\end{array}$ \\
\hline$\Delta V^{\text {Actual }}$ (Observed: $B$ by Firm 2) $>\Delta V^{C F}(C F$ : $B$ by Firm 3$)$ & create more \\
\hline$\Delta V^{\text {Acclual }}$ (Observed: $C$ by Firm 3$)>\triangle V C F(C F$; $C$ by Firm 1$)$ & $\begin{array}{l}\text { vaulue than } \\
\text { counterfactuals }\end{array}$ \\
\hline$\Delta V^{\text {Actual }}($ Observed: $\mathrm{C}$ by Firm 3$)>\Delta \mathrm{V}^{\mathrm{CF}}$ (CF 6: $\mathrm{C}$ by Firm 2), & \\
\hline
\end{tabular}

Figure 1. Creation of counterfactuals from observed data. 

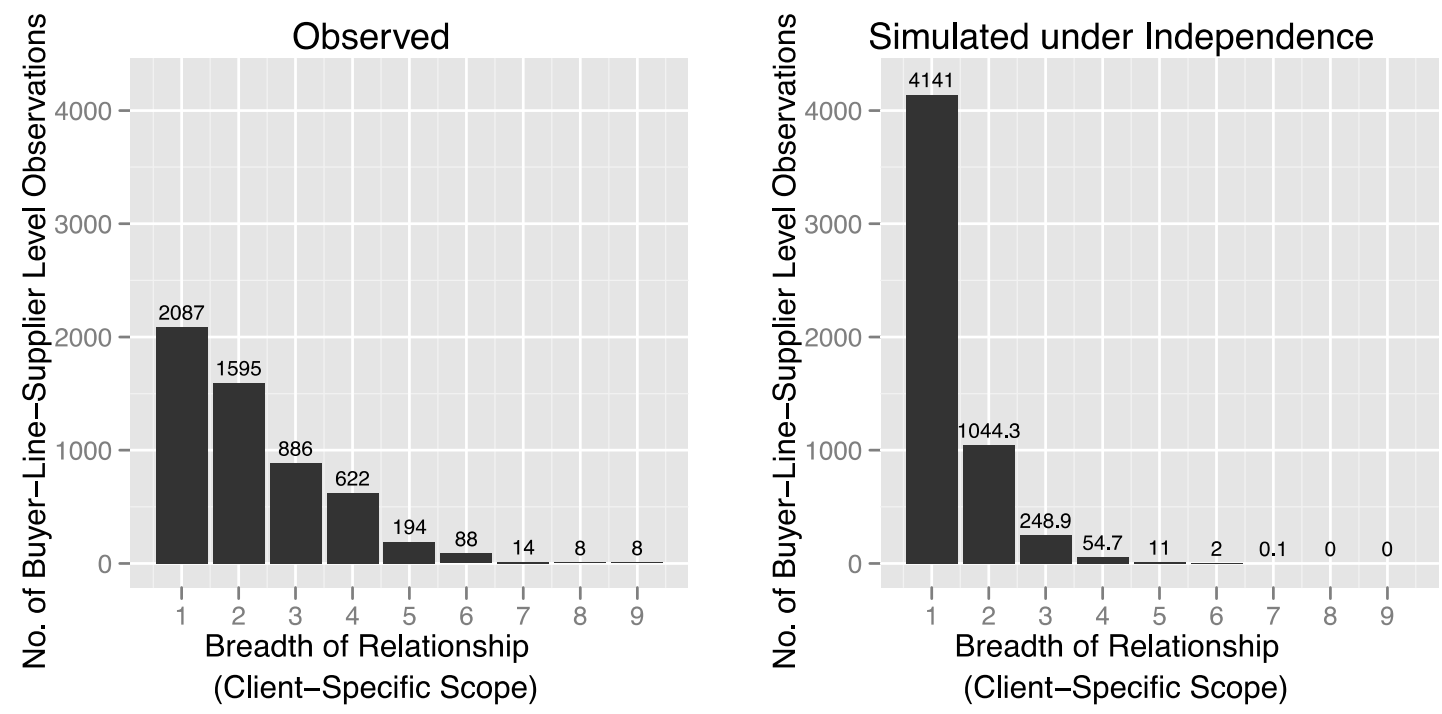

Figure 2. Observed and simulated client-specific scope.

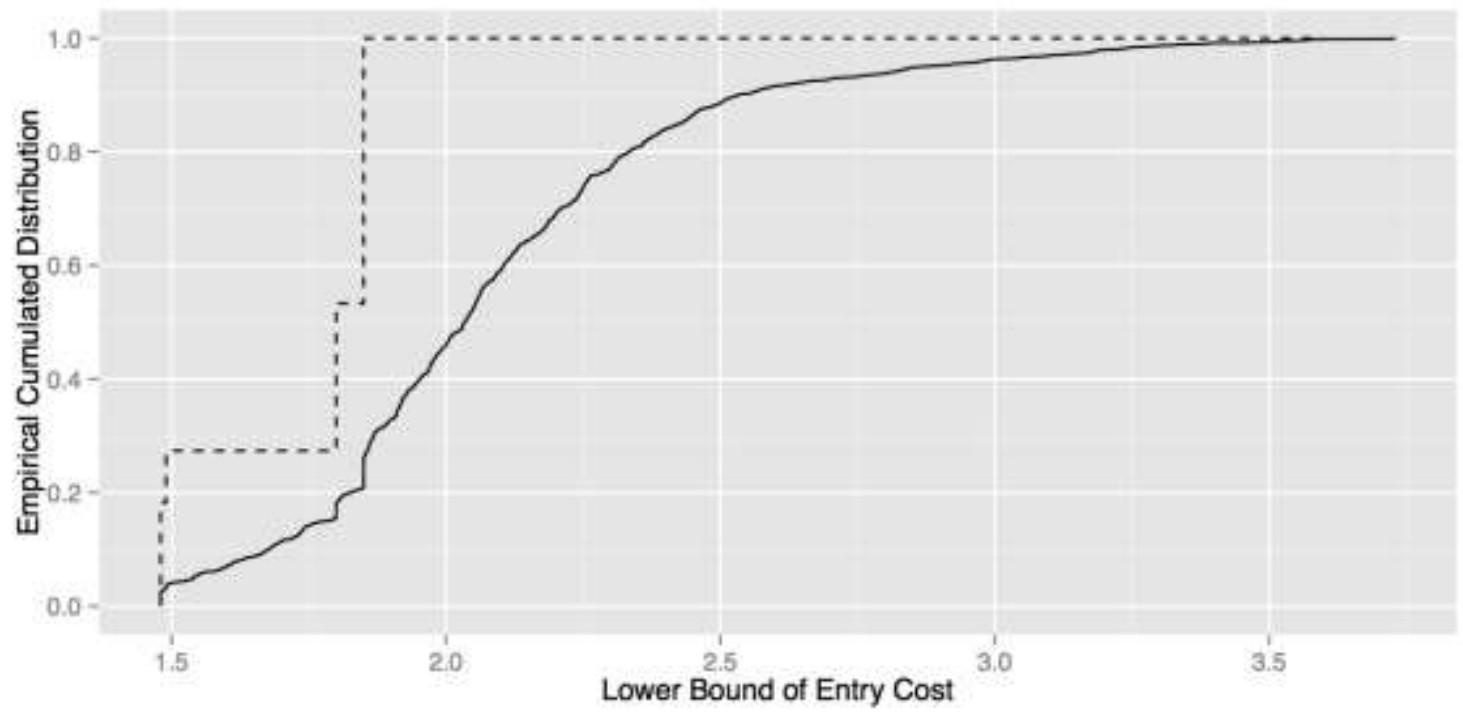

Figure 3: Empirical cumulative distribution function for lower bound of entry cost with best possible alternative supplier (solid line) and status quo supplier (broken line). The graph reads as follows: To explain $75 \%$ of the observed cases where there is no new relationship created, the cost of creating a new relationship needs to be at least equal to 1.85 if a new supplier is just as good as the existing one (broken line), or at least equal to 2.26 if the best outside supplier can be reached, and all errors terms are equal to zero. 